\title{
Two-Stage Fuzzy Portfolio Selection Problem with Transaction Costs
}

\author{
Yanju Chen and Ye Wang \\ College of Mathematics and Information Science, Hebei University, Baoding, Hebei 071002, China \\ Correspondence should be addressed to Yanju Chen; chen-yanju@163.com
}

Received 1 April 2015; Revised 6 July 2015; Accepted 29 July 2015

Academic Editor: Arman Ganji

Copyright (C) 2015 Y. Chen and Y. Wang. This is an open access article distributed under the Creative Commons Attribution License, which permits unrestricted use, distribution, and reproduction in any medium, provided the original work is properly cited.

This paper studies a two-period portfolio selection problem. The problem is formulated as a two-stage fuzzy portfolio selection model with transaction costs, in which the future returns of risky security are characterized by possibility distributions. The objective of the proposed model is to achieve the maximum utility in terms of the expected value and variance of the final wealth. Given the first-stage decision vector and a realization of fuzzy return, the optimal value expression of the second-stage programming problem is derived. As a result, the proposed two-stage model is equivalent to a single-stage model, and the analytical optimal solution of the two-stage model is obtained, which helps us to discuss the properties of the optimal solution. Finally, some numerical experiments are performed to demonstrate the new modeling idea and the effectiveness. The computational results provided by the proposed model show that the more risk-averse investor will invest more wealth in the risk-free security. They also show that the optimal invested amount in risky security increases as the risk-free return decreases and the optimal utility increases as the risk-free return increases, whereas the optimal utility increases as the transaction costs decrease. In most instances the utilities provided by the proposed two-stage model are larger than those provided by the single-stage model.

\section{Introduction}

In financial theory, portfolio selection finds a satisfying portfolio which allocates a certain amount of wealth among different securities. The first mathematical formulation of the portfolio selection problem is Markowitz's famous meanvariance model [1], which is based on probability theory. Markowitz's mean-variance theory is the foundation of modern portfolio analysis. In the mean-variance model, the returns of individual securities are taken as random variables and the expected value and variance of the return are taken as the investment return and risk, respectively. In two cases, the mean-variance model provides analytical solutions. One is the case that an investor maximizes his/her expected wealth without exceeding a predetermined risk level. Another case is that an investor minimizes his/her risk when ensuring predetermined wealth. The mean-variance model is a parametric optimization model to describe the single-period portfolio selection problem. In some cases, the investors may adjust their wealth allocation strategies during the investment horizon. Correspondingly, the investment horizon can be taken as several periods of time. So many researchers have studied the multiperiod portfolio selection problem in the framework of Markowitz's mean-variance theory, for example, Mossin [2], Dantzig and Infanger [3], $\mathrm{Li}$ and Ng [4], Çelikyurt and Özekici [5], Bertsimas and Pachamanova [6], and Cui et al. [7]. These researchers have formulated portfolio selection problems as stochastic programming models, where the returns of securities have been characterized by random variables.

When the returns of some securities can be estimated via subjective judgment in the decision-making stage, the investor may take experts' knowledge into account. For instance, the available (historical) data of the new securities which are listed in the stock market are incomplete; the returns of the new securities need to be estimated by experts or investors. In this case, decision makers can not get the exact probability distribution. But they are usually provided with information which is characterized by vague linguistic descriptions such as high risk, low profit, and high 
interest rate. Consequently, the portfolio selection problems are depicted as fuzzy optimization problems. On the basis of fuzzy theory [8-12], some researchers applied various fuzzy optimization methods to portfolio selection problem. Inuiguchi and Tanino [13] dealt with a portfolio selection problem with independently estimated possibilistic return rates and obtained a distributive investment. Bilbao-Terol et al. [14] formulated a fuzzy compromise programming problem to solve a portfolio selection problem by using Sharpe's single index model. Wu and Liu [15] took the spread as a new risk criterion in fuzzy decision systems, combined it with the expectation of fuzzy variable, and developed three classes of fuzzy expectation-spread models for portfolio optimization problems. Huang [16] proposed an entropy method for diversified fuzzy portfolio selection. The author introduced proportion entropy and proposed credibilistic mean-variance and mean-semivariance diversification models for fuzzy portfolio selection. Mehlawat and Gupta [17] addressed fuzzy portfolio selection problem from a perspective of chance constrained multiobjective programming. Deng and Li [18] proposed a biobjective nonlinear portfolio selection model, which aimed to maximize the future expected return and minimize the future expected risk. They also proposed a gradually tolerant constraint method to solve this model. Qian and Yin [19] proposed two new mathematical models by expressing divergence as distance, investment return as expected value, and risk as variance and semivariance, respectively. Li et al. [20] developed a fuzzy portfolio selection model with background risk.

In real financial market, transaction costs play a crucial role in the trading process. Since the transaction costs decrease the portfolio return, investors can not trade frequently. Therefore, the transaction costs affect the investor to make the investment policies. Ignoring the transaction costs, investors may fail to obtain the satisfying portfolio. Considering the transaction costs in portfolio adjusting process, Chen et al. [21] discussed a fuzzy portfolio adjusting problem. In the proposed model, the authors took the first possibilistic moment about zero of a portfolio as the investment return and the second possibilistic moment about the possibilistic mean value of the portfolio as the investment risk. Gupta et al. [22] proposed multicriteria credibilistic framework for fuzzy portfolio rebalancing problem by considering return, risk and liquidity as key financial criteria. Zhang et al. [23] dealt with a multiperiod portfolio selection problem with fuzzy returns and proposed a possibilistic mean-semivarianceentropy model. However, only a few researchers investigated multiperiod fuzzy portfolio selection problem. Thus far, to the best of our knowledge, there is no research on multiperiod fuzzy portfolio selection problem with two-stage fuzzy optimization methods. Two-stage fuzzy programming was introduced in 2005-it is an appropriate tool to study decision-making problems involving multiple stages.

Compared with the literature, the main contributions of this paper consist of the following four aspects. Firstly, this paper uses two-stage fuzzy optimization methods to formulate a novel class of two-period portfolio selection problems. The adopted optimization method distinguishes this research from other fuzzy portfolio selection models.
The first-stage decision is made when an investor enters the market; that is, the first-stage decision is made before the return is known. The investor can adjust the investment policy at the beginning of the second period. The adjustment amounts form the second-stage decision vector. For multiperiod fuzzy portfolio selection problem, there is no research in the literature to divide the investment horizon in this way. This division approach is more realistic and gives the investor an option to take recourse action (adjust the investment policy) at the second period. Secondly, considering the transaction costs in portfolio adjusting process, the proposed two-stage model is a more practical model for the investor. Solving the proposed two-stage model is a key issue. To overcome this crux, the proposed two-stage model is translated into an equivalent single-stage model by analyzing the second-stage programming problem. Then this paper provides the analytical optimal solution of the proposed model. The analytical optimal solution is the third one of this paper's main contributions. It provides a convenience to analyze different parameters' different effects on the optimal investment decision. Finally, the computational results of numerical experiments support the theoretical analysis. The proposed two-stage model provides higher utilities in most instances than the single-stage model.

The rest of the paper is organized as follows. Section 2 depicts a two-period portfolio selection problem. Section 3 proposes a two-stage fuzzy portfolio selection model with transaction costs. For the proposed two-stage model, Section 4 derives the analytical optimal decision vector. This section also discusses the properties of the optimal solution. Some numerical experiments are performed to demonstrate the new modeling idea and the effectiveness in Section 5. Section 6 concludes the paper.

\section{Problem Description}

An investor enters the market at time 0 with initial wealth $W$ and wants to allocate his/her wealth among one risky security and one risk-free security. The risky security is taken as security 1 , and the risk-free security is taken as security 0 . The investment horizon is divided into two periods. After the first period, observing the revenue performance of the risky security at the first period, the investor can adjust the investment policy at time 1 . At time 2, the second period ends and the investor exits the market. The investor aims to maximize the final wealth utility.

It is well known that the investor will decide the investment amount in the $i$ th security according to the return of the $i$ th security. But the investor can not know the returns well in the decision-making stage. Sometimes the returns of the risky security need to be estimated by experts or investors. They are characterized by vague linguistic descriptions such as high risk, low profit, and high interest rate. Consequently, this paper adopts possibility distributions to characterize the returns.

To optimize the portfolio selection problem, two-stage fuzzy optimization method is employed to model the investment decision-making. In the first-stage, the investor decides an original investment policy. In the second-stage, in order to 
obtain a better investment policy for the second period, the investor can take a recourse action.

The following assumptions are made to build the twostage fuzzy portfolio selection model:

(A1) All available wealth is invested.

(A2) Short sales are not permitted.

(A3) The whole investment process is self-financing; that is, the investor does not invest the additional wealth and also does not withdraw wealth in the whole investment process.

(A4) In the whole investment process, risk-free security has fixed return.

(A5) For the risky security, the returns in two different periods are independent of each other.

(A6) The investor is rational.

(A7) Transaction costs exist in the market but do not exist when trading the risk-free security.

\section{Formulation of Two-Stage Portfolio Selection Model}

In order to describe the two-stage fuzzy portfolio selection model conveniently, some notations are introduced in Notations.

3.1. The Second-Stage Model. Let the portfolio at the first period be $\mathbf{x}=\left(x_{0}, x_{1}\right)$. Then, at the end of the first period, the invested wealth corresponding to $x_{0}$ is $r_{0} x_{0}$, and the invested wealth corresponding to $x_{1}$ is $r_{1} x_{1}$.

At the second period, after observing the return $r_{1}(\theta)$ at the first period, but before knowing the return $r_{2}$ at the second period, the investor adjusts the investment policy for each security by increasing or decreasing the invested wealth amount. The adjustment can be regarded as a type of recourse action for $\mathbf{x}$. Since short sales are not permitted, the adjustment amount $y_{i}$ of the $i$ th security is such that

$$
\begin{aligned}
r_{0} x_{0}+y_{0} & \geq 0, \\
r_{1}(\theta) x_{1}+y_{1} & \geq 0 .
\end{aligned}
$$

The portfolio at the second period is $\left(r_{0} x_{0}+y_{0}, r_{1}(\theta) x_{1}+y_{1}\right)$. The whole transaction costs of all adjustment amounts are $C\left|y_{1}\right|$. As the whole investment process is self-financing, it is easy to see that all adjustment amounts are such that

$$
y_{0}+y_{1}+C\left|y_{1}\right|=0 \text {. }
$$

Therefore, for fixed $\mathbf{x}$ and $r_{1}(\theta)$, when the investor exits the market at time 2 , the final expected wealth is

$$
(1-C) E\left[r_{2}\left(r_{1}(\theta) x_{1}+y_{1}\right)\right]+r_{0}\left(r_{0} x_{0}+y_{0}\right) \text {. }
$$

In the investment process, since the market is affected by many factors, the returns are changing all the time. The investment decision-making can not wait for the realization of fuzzy returns. In other words, the portfolio $\mathbf{x}=\left(x_{0}, x_{1}\right)$, called the first-stage decision, must be made before knowing the realization of the fuzzy variable $r_{1}$, while the other decision, $\left(y_{0}, y_{1}\right)$, called the second-stage decision, can be made after the realization of the fuzzy variable $r_{1}$ is known. In this representation, the first-stage and second-stage are differentiated distinctly. The first-stage refers to the period of time before the fuzzy variable $r_{1}$ is known. Correspondingly, the second-stage refers to the period of time after the fuzzy variable $r_{1}$ is known. In the second-stage, the decrease on the risk-free security must not be more than $r_{0} x_{0}$ at the first period. In the same way, the decrease on the risky security must not be more than $r_{1} x_{1}$.

As a consequence, when the first-stage decision vector $\mathbf{x}$ is given, and a realization $r_{1}(\theta)$ of the fuzzy vector $r_{1}$ is known, the second-stage programming of the portfolio selection model reads

$$
\begin{array}{cl}
\operatorname{maximize} & (1-C) E\left[r_{2}\left(r_{1}(\theta) x_{1}+y_{1}\right)\right] \\
& +r_{0}\left(r_{0} x_{0}+y_{0}\right) \\
\text { subject to } & y_{0}+y_{1}+C\left|y_{1}\right|=0 \\
& r_{1}(\theta) x_{1}+y_{1} \geq 0 \\
& r_{0} x_{0}+y_{0} \geq 0 .
\end{array}
$$

The objective of second-stage programming (4) is to maximize the expected wealth at the end of the second period for the fixed $\mathbf{x}$ and $r_{1}(\theta)$. In the following of this paper, $Q\left(\mathbf{x}, r_{1}(\theta)\right)$ denotes the optimal value of second-stage programming (4).

3.2. The First-Stage Model. The objective of the investor is to maximize the final expected wealth over the whole investment horizon, while minimizing the risk corresponding to the final expected wealth as far as possible. So the investment policies are made to maximize the following utility function

$$
E_{r_{1}}\left[Q\left(\mathbf{x}, r_{1}(\theta)\right)\right]-\lambda D_{r_{1}}\left[Q\left(\mathbf{x}, r_{1}(\theta)\right)\right]
$$

where $\lambda$ is the risk aversion coefficient, $E$ is the expected value operator of a fuzzy variable [11], and $D$ is the variance operator of a fuzzy variable [11]. $E_{r_{1}}\left[Q\left(\mathbf{x}, r_{1}(\theta)\right)\right]$ is taken as the final expected wealth, and $D_{r_{1}}\left[Q\left(\mathbf{x}, r_{1}(\theta)\right)\right]$ is taken as the corresponding risk. Here the utility function is a recourse function. The larger $\lambda$ implies that the investor is more riskaverse.

In the first-stage, since the transaction costs do not exist in the trade of risk-free security, all available wealth is invested and short sales are not permitted; the portfolio $\mathbf{x}=\left(x_{0}, x_{1}\right)$ at the first period satisfies the following conditions:

$$
x_{0}+(1+C) x_{1}=W, \quad x_{i} \geq 0, i=0,1 .
$$


Using the notations above, the first-stage programming of the portfolio selection model is

$$
\begin{array}{ll}
\operatorname{maximize} & E_{r_{1}}\left[Q\left(\mathbf{x}, r_{1}(\theta)\right)\right]-\lambda D_{r_{1}}\left[Q\left(\mathbf{x}, r_{1}(\theta)\right)\right] \\
\text { subject to } & x_{0}+(1+C) x_{1}=W \\
& x_{i} \geq 0, \quad i=0,1 .
\end{array}
$$

Remark 1. According to B. Liu and Y.-K. Liu [11], the expected value of a fuzzy variable is defined via Choquet integral, which is a scalar value. It is also applicable to a function of a fuzzy variable. Let $\xi$ be a fuzzy variable with a possibility distribution function $\mu$. Then the credibility of fuzzy event $\{\xi \leq p\}$ is defined by $\operatorname{Cr}\{\xi \leq p\}=$ $(1 / 2)\left(\sup _{t \in R} \mu(t)+\sup _{t \leq p} \mu(t)-\sup _{t>p} \mu(t)\right), p \in R$. And $\operatorname{Cr}\{\xi \geq p\}=(1 / 2)\left(\sup _{t \in R} \mu(t)+\sup _{t \geq p} \mu(t)-\sup _{t<p} \mu(t)\right), p \in$ $R$. The expected value of fuzzy variable $\xi$ is defined as $E[\xi]=\int_{0}^{\infty} \operatorname{Cr}\{\xi \geq p\} \mathrm{d} p-\int_{-\infty}^{0} \operatorname{Cr}\{\xi \leq p\} \mathrm{d} p$ provided that at least one of the two integrals is finite. Fuzzy variable $(\xi-E[\xi])^{2}$ is a function of $\xi$. Its possibility distribution function can be obtained by Extension Principle of Zadeh. If $E[\xi]$ is finite, the variance of fuzzy variable $\xi$ is defined as the expected value of $(\xi-E[\xi])^{2}$; that is, $D[\xi]=E\left[(\xi-E[\xi])^{2}\right]$.

3.3. A New Two-Stage Portfolio Selection Model. Combining models (4) and (7), a two-stage fuzzy portfolio selection model is formally built as follows:

$$
\begin{array}{cl}
\operatorname{maximize} & E_{r_{1}}\left[Q\left(\mathbf{x}, r_{1}(\theta)\right)\right]-\lambda D_{r_{1}}\left[Q\left(\mathbf{x}, r_{1}(\theta)\right)\right] \\
\text { subject to } & x_{0}+(1+C) x_{1}=W \\
& x_{i} \geq 0, \quad i=0,1
\end{array}
$$

where

$$
\begin{aligned}
Q\left(\mathbf{x}, r_{1}(\theta)\right)=\operatorname{maximize} & (1-C) E\left[r_{2}\left(r_{1}(\theta) x_{1}+y_{1}\right)\right]+r_{0}\left(r_{0} x_{0}+y_{0}\right) \\
\text { subject to } & y_{0}+y_{1}+C\left|y_{1}\right|=0 \\
& r_{1}(\theta) x_{1}+y_{1} \geq 0 \\
& r_{0} x_{0}+y_{0} \geq 0
\end{aligned}
$$

From the practical standpoint, for any $\mathbf{x}$ that satisfy deterministic constraints (6), second-stage programming (4) has feasible solutions.

Since the returns of risky security in two periods are independent of each other, it is easy to see that model (8) is equivalent to the following model:

$$
\begin{array}{ll}
\operatorname{maximize} & E_{r_{1}}\left[Q\left(\mathbf{x}, r_{1}(\theta)\right)\right]-\lambda D_{r_{1}}\left[Q\left(\mathbf{x}, r_{1}(\theta)\right)\right] \\
\text { subject to } & x_{0}+(1+C) x_{1}=W \\
& x_{i} \geq 0, \quad i=0,1
\end{array}
$$

where

$$
\begin{aligned}
Q\left(\mathbf{x}, r_{1}(\theta)\right)=\operatorname{maximize} & (1-C) E\left[r_{2}\right]\left(r_{1}(\theta) x_{1}+y_{1}\right)+r_{0}\left(r_{0} x_{0}+y_{0}\right) \\
\text { subject to } & y_{0}+y_{1}+C\left|y_{1}\right|=0 \\
& r_{1}(\theta) x_{1}+y_{1} \geq 0 \\
& r_{0} x_{0}+y_{0} \geq 0
\end{aligned}
$$

Remark 2. Since financial market is complex and affected by many factors including economic, social, political, and people's psychological factors, in many cases the future return of risky security can not be accurately predicted by its historical data. For instance, the available (historical) data of the new securities which are listed in the stock market are incomplete; the returns of the new securities need to be estimated by experts or investors. In this case, the returns are usually provided with information which is characterized by vague linguistic descriptions such as high risk, low profit, and high interest rate. A fuzzy variable is an appropriate tool to characterize the vague linguistic description. In two-stage model (10) and (11), the uncertain returns are characterized as two fuzzy variables with the known possibility distributions. The possibility distribution are given on the basis of the available historical data and the advice of experts. Thus the possibility distribution is practical. Two-stage model (10) and (11) gives the investor an option to take recourse action. So the proposed two-stage fuzzy portfolio selection model is superior to the conventional model. 


\section{Model Analysis}

Firstly the second-stage programming is solved for the given first-stage decision vector $\mathbf{x}$ and known realization $r_{1}(\theta)$. Then the optimal first-stage decision vector is deduced.
4.1. The Optimal Value of the Second-Stage Model. According to the objective function expression of model (11), if (1 C) $E\left[r_{2}\right]>r_{0}$, then $y_{1} \geq 0$ and $y_{0} \leq 0$. Hence model (11) is equivalent to

$$
\begin{aligned}
Q\left(\mathbf{x}, r_{1}(\theta)\right)=\text { maximize } & (1-C) E\left[r_{2}\right]\left(r_{1}(\theta) x_{1}+y_{1}\right)+r_{0}\left(r_{0} x_{0}+y_{0}\right) \\
\text { subject to } & y_{0}+(1+C) y_{1}=0 \\
& -r_{0} x_{0} \leq y_{0} \leq 0
\end{aligned}
$$

Furthermore, model (12) is equivalent to

$$
\begin{aligned}
Q\left(\mathbf{x}, r_{1}(\theta)\right)= & \text { maximize }(1-C) E\left[r_{2}\right] r_{1}(\theta) x_{1}+r_{0}^{2} x_{0}+\left(r_{0}-\frac{1-C}{1+C} E\left[r_{2}\right]\right) y_{0} \\
& \text { subject to }-r_{0} x_{0} \leq y_{0} \leq 0
\end{aligned}
$$

So

$$
Q\left(\mathbf{x}, r_{1}(\theta)\right)= \begin{cases}(1-C) E\left[r_{2}\right] r_{1}(\theta) x_{1}+\frac{1-C}{1+C} E\left[r_{2}\right] r_{0} x_{0}, & \text { if } r_{0}<\frac{1-C}{1+C} E\left[r_{2}\right] \\ (1-C) E\left[r_{2}\right] r_{1}(\theta) x_{1}+r_{0}^{2} x_{0}, & \text { if } r_{0} \geq \frac{1-C}{1+C} E\left[r_{2}\right] .\end{cases}
$$

If $(1-C) E\left[r_{2}\right] \leq r_{0}$, then $y_{1} \leq 0$ and $y_{0} \geq 0$. It follows that model (11) is equivalent to

$$
\begin{aligned}
Q\left(\mathbf{x}, r_{1}(\theta)\right)=\text { maximize } & (1-C) E\left[r_{2}\right]\left(r_{1}(\theta) x_{1}+y_{1}\right)+r_{0}\left(r_{0} x_{0}+y_{0}\right) \\
\text { subject to } & y_{0}+(1-C) y_{1}=0 \\
& -r_{1}(\theta) x_{1} \leq y_{1} \leq 0
\end{aligned}
$$

Furthermore, model (15) is equivalent to

$$
\begin{aligned}
Q\left(\mathbf{x}, r_{1}(\theta)\right)= & \text { maximize }(1-C) E\left[r_{2}\right] r_{1}(\theta) x_{1}+r_{0}^{2} x_{0}+(1-C)\left(E\left[r_{2}\right]-r_{0}\right) y_{1} \\
& \text { subject to }-r_{1}(\theta) x_{1} \leq y_{1} \leq 0 .
\end{aligned}
$$

As a consequence,

$$
\begin{aligned}
& Q\left(\mathbf{x}, r_{1}(\theta)\right) \\
& \quad= \begin{cases}(1-C) r_{0} r_{1}(\theta) x_{1}+r_{0}^{2} x_{0}, & \text { if } r_{0} \geq E\left[r_{2}\right] \\
(1-C) E\left[r_{2}\right] r_{1}(\theta) x_{1}+r_{0}^{2} x_{0}, & \text { if } r_{0} \leq E\left[r_{2}\right] .\end{cases}
\end{aligned}
$$

The following theorem summarizes the results obtained above.

Theorem 3. For model (11), the following assertions about the optimal value are valid:

(i) If $0<r_{0}<((1-C) /(1+C)) E\left[r_{2}\right]$-that is, $E\left[r_{2}\right]>$ $((1+C) /(1-C)) r_{0}$-then the optimal value is

$$
\begin{aligned}
Q\left(\mathbf{x}, r_{1}(\theta)\right)= & (1-C) E\left[r_{2}\right] r_{1}(\theta) x_{1} \\
& +\frac{1-C}{1+C} E\left[r_{2}\right] r_{0} x_{0} .
\end{aligned}
$$


(ii) If $((1-C) /(1+C)) E\left[r_{2}\right] \leq r_{0} \leq E\left[r_{2}\right]$-that is, $r_{0} \leq$ $E\left[r_{2}\right] \leq((1+C) /(1-C)) r_{0}$-then the optimal value is

$$
Q\left(\mathbf{x}, r_{1}(\theta)\right)=(1-C) E\left[r_{2}\right] r_{1}(\theta) x_{1}+r_{0}^{2} x_{0} \text {. }
$$

(iii) If $r_{0}>E\left[r_{2}\right]$, then the optimal value is

$$
Q\left(\mathbf{x}, r_{1}(\theta)\right)=(1-C) r_{0} r_{1}(\theta) x_{1}+r_{0}^{2} x_{0} .
$$

4.2. The Optimal Solution of the Two-Stage Model. Substituting the optimal value of model (11) into model (10), the twostage model (10) and (11) is equivalent to a single-stage model. Then model (10) can be solved by dividing the equivalent single-stage model into three submodels.

Case $1\left(E\left[r_{2}\right]>((1+C) /(1-C)) r_{0}\right)$. According to B. Liu and Y.-K. Liu [11] and (18) model (10) can be written as

$$
\begin{aligned}
\operatorname{maximize} \quad(1-C) E\left[r_{2}\right] E\left[r_{1}\right] x_{1} \\
\quad+\frac{1-C}{1+C} E\left[r_{2}\right] r_{0} x_{0} \\
-\lambda(1-C)^{2} E\left[r_{2}\right]^{2} D\left[r_{1}\right] x_{1}^{2}
\end{aligned}
$$

subject to $x_{0}+(1+C) x_{1}=W$

$$
x_{i} \geq 0, \quad i=0,1 \text {. }
$$

It is equivalent to the following model:

$$
\begin{aligned}
& \operatorname{maximize} \quad U\left(x_{1}\right) \\
&=\frac{1-C}{1+C} E\left[r_{2}\right] r_{0} W \\
&+(1-C) E\left[r_{2}\right]\left(E\left[r_{1}\right]-r_{0}\right) x_{1} \\
&-\lambda(1-C)^{2} E\left[r_{2}\right]^{2} D\left[r_{1}\right] x_{1}^{2}
\end{aligned}
$$

subject to $0 \leq x_{1} \leq \frac{W}{1+C}$.

The objective function $U\left(x_{1}\right)$ gets its maximum value at $x_{1}^{\prime}=$ $\left(E\left[r_{1}\right]-r_{0}\right) / 2 \lambda(1-C) E\left[r_{2}\right] D\left[r_{1}\right]$. Considering the constraint condition, the optimal solution $x_{1}^{*}=0$ when $x_{1}^{\prime} \leq 0$, and $x_{1}^{*}=W /(1+C)$ when $x_{1}^{\prime} \geq W /(1+C)$.

Therefore, Theorem 4 is obtained as follows.

Theorem 4. For model (10), the following assertions about the optimal solution are valid:

(i) If $E\left[r_{2}\right]>((1+C) /(1-C)) r_{0}$ and $\left(E\left[r_{1}\right]-r_{0}\right) E\left[r_{2}\right] \leq 0$, then the optimal solution is

$$
\begin{aligned}
& x_{0}^{*}=W, \\
& x_{1}^{*}=0 .
\end{aligned}
$$

(ii) If $E\left[r_{2}\right]>((1+C) /(1-C)) r_{0}$ and $\left(E\left[r_{1}\right]-r_{0}\right) / 2 \lambda(1-$ C) $E\left[r_{2}\right] D\left[r_{1}\right] \geq W /(1+C)$, then the optimal solution is

$$
\begin{aligned}
& x_{0}^{*}=0, \\
& x_{1}^{*}=\frac{W}{1+C} .
\end{aligned}
$$

(iii) If $E\left[r_{2}\right]>((1+C) /(1-C)) r_{0}$ and $0<\left(E\left[r_{1}\right]-r_{0}\right) / 2 \lambda(1-$ C) $E\left[r_{2}\right] D\left[r_{1}\right]<W /(1+C)$, then the optimal solution is

$$
\begin{aligned}
& x_{0}^{*}=W-\frac{(1+C)\left(E\left[r_{1}\right]-r_{0}\right)}{2 \lambda(1-C) E\left[r_{2}\right] D\left[r_{1}\right]}, \\
& x_{1}^{*}=\frac{E\left[r_{1}\right]-r_{0}}{2 \lambda(1-C) E\left[r_{2}\right] D\left[r_{1}\right]} .
\end{aligned}
$$

Case $2\left(r_{0} \leq E\left[r_{2}\right] \leq((1+C) /(1-C)) r_{0}\right)$. In this case, according to B. Liu and Y.-K. Liu [11] and (19), model (10) can be written as

$$
\begin{array}{ll}
\text { maximize } & (1-C) E\left[r_{2}\right] E\left[r_{1}\right] x_{1}+r_{0}^{2} x_{0} \\
& -\lambda(1-C)^{2} E\left[r_{2}\right]^{2} D\left[r_{1}\right] x_{1}^{2} \\
\text { subject to } & x_{0}+(1+C) x_{1}=W \\
& x_{i} \geq 0, \quad i=0,1 .
\end{array}
$$

Its equivalent form is as follows:

$$
\begin{array}{ll}
\operatorname{maximize} \quad U\left(x_{1}\right) \\
=r_{0}^{2} W+(1-C) E\left[r_{2}\right] E\left[r_{1}\right] x_{1} \\
& -r_{0}^{2}(1+C) x_{1} \\
& -\lambda(1-C)^{2} E\left[r_{2}\right]^{2} D\left[r_{1}\right] x_{1}^{2} \\
\text { subject to } \quad 0 \leq & x_{1} \leq \frac{W}{1+C} .
\end{array}
$$

It is easy to know that $U\left(x_{1}\right)$ gets its maximum value at $x_{1}^{\prime}=$ $\left((1-C) E\left[r_{2}\right] E\left[r_{1}\right]-r_{0}^{2}(1+C)\right) / 2 \lambda(1-C)^{2} E\left[r_{2}\right]^{2} D\left[r_{1}\right]$. From the constraint condition, the optimal solution $x_{1}^{*}=0$ when $x_{1}^{\prime} \leq 0$, and $x_{1}^{*}=W /(1+C)$ when $x_{1}^{\prime} \geq W /(1+C)$. These are summarized in Theorem 5 .

Theorem 5. For model (10), the following assertions about the optimal solution are valid:

(i) If $r_{0} \leq E\left[r_{2}\right] \leq((1+C) /(1-C)) r_{0}$ and $((1-C) /(1+$ C)) $E\left[r_{2}\right] E\left[r_{1}\right] \leq r_{0}^{2}$, then the optimal solution is

$$
\begin{aligned}
& x_{0}^{*}=W, \\
& x_{1}^{*}=0 .
\end{aligned}
$$

(ii) If $r_{0} \leq E\left[r_{2}\right] \leq((1+C) /(1-C)) r_{0}$ and $((1-$ C) $\left.E\left[r_{2}\right] E\left[r_{1}\right]-r_{0}^{2}(1+C)\right) / 2 \lambda(1-C)^{2} E\left[r_{2}\right]^{2} D\left[r_{1}\right] \geq$ $W /(1+C)$, then the optimal solution is

$$
\begin{aligned}
& x_{0}^{*}=0, \\
& x_{1}^{*}=\frac{W}{1+C} .
\end{aligned}
$$


(iii) If $r_{0} \leq E\left[r_{2}\right] \leq((1+C) /(1-C)) r_{0}$ and $0 \leq((1-$ C) $\left.E\left[r_{2}\right] E\left[r_{1}\right]-r_{0}^{2}(1+C)\right) / 2 \lambda(1-C)^{2} E\left[r_{2}\right]^{2} D\left[r_{1}\right] \leq$ $W /(1+C)$, then the optimal solution is

$$
\begin{aligned}
& x_{0}^{*}=W-\frac{\left(1-C^{2}\right) E\left[r_{2}\right] E\left[r_{1}\right]-r_{0}^{2}(1+C)^{2}}{2 \lambda(1-C)^{2} E\left[r_{2}\right]^{2} D\left[r_{1}\right]}, \\
& x_{1}^{*}=\frac{(1-C) E\left[r_{2}\right] E\left[r_{1}\right]-r_{0}^{2}(1+C)}{2 \lambda(1-C)^{2} E\left[r_{2}\right]^{2} D\left[r_{1}\right]} .
\end{aligned}
$$

Case $3\left(E\left[r_{2}\right]<r_{0}\right)$. According to B. Liu and Y.-K. Liu [11] and (20) model (10) can be written as

$$
\begin{array}{cl}
\operatorname{maximize} & (1-C) r_{0} E\left[r_{1}\right] x_{1}+r_{0}^{2} x_{0} \\
& -\lambda(1-C)^{2} r_{0}^{2} D\left[r_{1}\right] x_{1}^{2} \\
\text { subject to } & x_{0}+(1+C) x_{1}=W \\
& x_{i} \geq 0, \quad i=0,1 .
\end{array}
$$

It is equivalent to the following model:

$$
\begin{aligned}
& \text { maximize } U\left(x_{1}\right) \\
& =r_{0}^{2} \mathrm{~W} \\
& +\left((1-C) E\left[r_{1}\right]-(1+C) r_{0}\right) r_{0} x_{1} \\
& -\lambda(1-C)^{2} r_{0}^{2} D\left[r_{1}\right] x_{1}^{2} \\
& \text { subject to } 0 \leq x_{1} \leq \frac{W}{1+C} \text {. }
\end{aligned}
$$

The objective function $U\left(x_{1}\right)$ gets its maximum value at $x_{1}^{\prime}=$ $\left((1-C) E\left[r_{1}\right]-(1+C) r_{0}\right) / 2 \lambda(1-C)^{2} r_{0} D\left[r_{1}\right]$. Considering the constraint condition, the optimal solution $x_{1}^{*}=0$ when $x_{1}^{\prime} \leq 0$, and $x_{1}^{*}=W /(1+C)$ when $x_{1}^{\prime} \geq W /(1+C)$. These are summarized in Theorem 6 .

Theorem 6. For model (10), the following assertions about the optimal solution are valid:

(i) If $E\left[r_{2}\right]<r_{0}$ and $((1-C) /(1+C)) E\left[r_{1}\right] \leq r_{0}$, then the optimal solution is

$$
\begin{aligned}
& x_{0}^{*}=W, \\
& x_{1}^{*}=0 .
\end{aligned}
$$

(ii) If $E\left[r_{2}\right]<r_{0}$ and $\left((1-C) E\left[r_{1}\right]-(1+C) r_{0}\right) / 2 \lambda(1-$ $C)^{2} r_{0} D\left[r_{1}\right] \geq W /(1+C)$, then the optimal solution is

$$
\begin{aligned}
& x_{0}^{*}=0, \\
& x_{1}^{*}=\frac{W}{1+C} .
\end{aligned}
$$

(iii) If $E\left[r_{2}\right]<r_{0}$ and $0<\left((1-C) E\left[r_{1}\right]-(1+C) r_{0}\right) / 2 \lambda(1-$ $C)^{2} r_{0} D\left[r_{1}\right]<W /(1+C)$, then the optimal solution is

$$
\begin{aligned}
& x_{0}^{*}=W-\frac{\left(1-C^{2}\right) E\left[r_{1}\right]-(1+C)^{2} r_{0}}{2 \lambda(1-C)^{2} r_{0} D\left[r_{1}\right]}, \\
& x_{1}^{*}=\frac{(1-C) E\left[r_{1}\right]-(1+C) r_{0}}{2 \lambda(1-C)^{2} r_{0} D\left[r_{1}\right]} .
\end{aligned}
$$

Remark 7. For the optimal solution of model (10), the following assertions are valid:

(i) $x_{1}^{*}$ is increasing with respect to $E\left[r_{1}\right]$.

(ii) $x_{1}^{*}$ is decreasing with respect to $\lambda$.

(iii) $x_{1}^{*}$ is decreasing with respect to $r_{0}$.

(iv) $x_{1}^{*}$ is decreasing with respect to $D\left[r_{1}\right]$.

Remark 8. If $E\left[r_{2}\right]>((1+C) /(1-C)) r_{0}$ and $0<$ $\left(E\left[r_{1}\right]-r_{0}\right) / 2 \lambda(1-C) E\left[r_{2}\right] D\left[r_{1}\right]<W /(1+C)$, then the optimal solution of model (10)- $x_{1}^{*}=\left(E\left[r_{1}\right]-r_{0}\right) / 2 \lambda(1-$ C) $E\left[r_{2}\right] D\left[r_{1}\right]$-is decreasing with respect to $E\left[r_{2}\right]$.

When the returns are characterized by triangular fuzzy variables, trapezoid fuzzy variables, and normal fuzzy variables, their expected value and variance can be computed with formulas accurately [11]. In the next section, the returns are characterized by triangular fuzzy variables. Let $r=$ $(a, b, c)$ be a triangular fuzzy variable. Then its expected value is $E[r]=(a+2 b+c) / 4$. If $b-a \geq c-b$, the variance is $D[r]=\left(33(b-a)^{3}+11(b-a)(c-b)^{2}+21(b-a)^{2}(c-b)-\right.$ $\left.(c-b)^{3}\right) / 384(b-a)$. Otherwise, $D[r]=\left(33(c-b)^{3}+11(b-\right.$ $\left.a)^{2}(c-b)+21(b-a)(c-b)^{2}-(b-a)^{3}\right) / 384(c-b)$.

\section{Numerical Experiments and Comparison Study}

5.1. Statement of Problem. In this section, a two-period portfolio selection problem is considered. Here let assumptions (A1)-(A7) in Section 2 stand. One period refers to 35 days. One day an investor enters the stock market with initial wealth $W=100$. The investor wants to allocate his/her wealth between one stock of Chinese Shanghai A-shares market and one risk-free security. After the first period, the investor can adjust the investment policy. At the end of the second period, the investment process ends. The investor aims to maximize the final wealth utility. The investor's securities account is in China Development Bank Securities. The transaction costs mainly include stamp tax, commission, and transfer fee. Stamp tax is 1 per thousand of turnovers and is charged only when selling stock. Commission is 1-3 per thousand of turnovers, and the lowest single transaction commission is $5 \mathrm{RMB}$. Transfer fee is $0.6 \mathrm{RMB}$ per thousand of the traded shares; the lowest transfer fee is $1 \mathrm{RMB}$. According to these rules, the transaction costs rate is assumed to be $C=0.003$. The transaction costs rate takes different values only in the experiments which illustrate the influence of the transaction costs on the optimal utility. In the literature [23], the transaction costs rate took the value 0.003 . 
TABLE 1: Triangular possibility distributions of fuzzy returns of 10 stocks.

\begin{tabular}{|c|c|c|c|c|c|c|}
\hline Case & $r_{1}$ & $r_{2}$ & $E\left[r_{1}\right]$ & $D\left[r_{1}\right]$ & $E\left[r_{2}\right]$ & $D\left[r_{2}\right]$ \\
\hline (1) & $(0.995,1.025,1.035)$ & $(0.884,1.008,1.017)$ & 1.02 & 0.00010 & 0.97925 & 0.00138 \\
\hline (2) & $(0.88,1.04,1.11)$ & $(0.884,1.036,1.117)$ & 1.0175 & 0.00295 & 1.01825 & 0.00284 \\
\hline (3) & $(0.895,1.024,1.082)$ & $(0.885,1.036,1.115)$ & 1.00625 & 0.00193 & 1.018 & 0.00278 \\
\hline (4) & $(0.91,1.012,1.076)$ & $(0.894,1.03,1.1)$ & 1.0025 & 0.00136 & 1.0135 & 0.00224 \\
\hline (5) & $(0.877,1.04,1.1)$ & $(0.89,1.022,1.1)$ & 1.01425 & 0.00292 & 1.0085 & 0.00223 \\
\hline (6) & $(0.879,1.04,1.1)$ & $(0.89,1.003,1.01)$ & 1.01475 & 0.00286 & 0.9765 & 0.00114 \\
\hline (7) & $(0.906,1.014,1.08)$ & $(0.892,1.03,1.085)$ & 1.0035 & 0.00151 & 1.00925 & 0.00214 \\
\hline (8) & $(0.973,1.04,1.12)$ & $(0.887,1.015,1.113)$ & 1.04325 & 0.00096 & 1.0075 & 0.00235 \\
\hline (9) & $(0.882,1.039,1.11)$ & $(0.902,1.026,1.09)$ & 1.0175 & 0.00287 & 1.011 & 0.00187 \\
\hline (10) & $(0.904,1.025,1.09)$ & $(0.882,1.038,1.117)$ & 1.011 & 0.00180 & 1.01875 & 0.00294 \\
\hline
\end{tabular}

The investor selects 10 stocks of Chinese Shanghai Ashares market (600004, 600007, 600018, 600023, 600059, $600081,600115,600139,600158$, and 600173). The 10 stocks are also denoted by $1,2,3,4,5,6,7,8,9$, and 10 . The investor has collected the stocks' historical data, which include the open prices, the highest prices, the lowest prices, and the close prices of some historical trading days (from March 2014 to February 2015). Based on these data, now the returns are characterized by triangular possibility distributions $\left(a_{i, 1}, b_{i, 1}, c_{i, 1}\right),\left(a_{i, 2}, b_{i, 2}, c_{i, 2}\right), i=1,2, \ldots, 10$, where subscript 1 denotes the first period and subscript 2 denotes the second period. This way of fitting data can be seen in the literature $[19,24,25]$. Simple triangular possibility distributions work well and are most frequently used in most practical applications. A theoretical explanation for why triangular functions work well was provided in [26]. Based on the ideas of the estimation methods in $[19,24,25]$, now the method of estimating the parameters of triangular possibility distributions is proposed as follows. For stock $i$, based on the historical data in March 2014, the ratio of the lowest price of the month to the open price on the first trading day can be obtained. In the same way, based on the historical data from April 2014 to February 2015, 11 ratios are obtained monthly in turn. These 12 ratios are ranked monthly. Parameter $a_{i, 1}$ is estimated according to the mean of the first 6 ratios, and parameter $a_{i, 2}$ is estimated according to the mean of the last 6 ratios. In the same way, $b_{i, 1}$ and $b_{i, 2}$ are estimated according to the 12 ratios of the close price on the last trading day to the open price on the first trading day, which are obtained monthly. Parameters $c_{i, 1}$ and $c_{i, 2}$ are estimated according to the 12 ratios of the monthly highest price to the open price on the first trading day of the month. In practice, the future returns of the securities, that is, the open price, the highest price, the lowest price, and the close price of a specific day, can not be exactly reflected by the historical data since they will be affected by many factors. Here the future returns are estimated based on the real historical data and the estimated values of stock experts. Table 1 lists these triangular possibility distributions and their expected values and variances. Let $x_{1}$ be the wealth amount invested in the stock.

5.2. Computational Results with the Two-Stage Model. The risk-free security is a principal-protected financial product with holding period of 35 days. Its annualized return rate is 0.0365 ; that is, $r_{0}=1.0035$. As an example, we consider the case that the returns of the stock 600004 are $r_{1}=$ $(0.995,1.025,1.035)$ and $r_{2}=(0.884,1.008,1.017)$. The returns are mutually independent and shown in Table 1 as "case (1)." The investor wants to invest in this stock. Let $\lambda=$ 0.1 . Then $E\left[r_{2}\right]=0.97925<r_{0}$, and $\left((1-C) E\left[r_{1}\right]-(1+\right.$ C) $\left.r_{0}\right) / 2 \lambda(1-C)^{2} r_{0} D\left[r_{1}\right]=555.0055>W /(1+C) \approx 99.7$. By Theorem 6 ,

$$
x_{1}^{*}=\frac{W}{1+C}=99.7
$$

According to the definition of utility and its expression in model (32), the final utility is

$$
\begin{aligned}
U\left(x_{1}^{*}\right)= & r_{0}^{2} W+\left((1-C) E\left[r_{1}\right]-(1+C) r_{0}\right) r_{0} x_{1}^{*} \\
& -\lambda(1-C)^{2} r_{0}^{2} D\left[r_{1}\right]\left(x_{1}^{*}\right)^{2}=101.6486
\end{aligned}
$$

We next consider the case that the investor selects the stock 600018 to invest in. The returns $r_{1}=(0.895,1.024,1.082)$ and $r_{2}=(0.885,1.036,1.115)$ are mutually independent and shown in Table 1 as "case (3)." Let $\lambda=0.1$. By calculating, $r_{0}<((1-C) /(1+C)) E\left[r_{2}\right]=1.01191$, and $\left(E\left[r_{1}\right]-r_{0}\right) / 2 \lambda(1-C) E\left[r_{2}\right] D\left[r_{1}\right]=7.0133<W /(1+C) \approx$ 99.7. On the basis of Theorem 4 ,

$$
x_{1}^{*}=\frac{E\left[r_{1}\right]-r_{0}}{2 \lambda(1-C) E\left[r_{2}\right] D\left[r_{1}\right]}=7.0133 .
$$

According to the definition of utility and its expression in model (22), the final utility is

$$
\begin{aligned}
U\left(x_{1}^{*}\right)= & \frac{1-C}{1+C} E\left[r_{2}\right] r_{0} W \\
& +(1-C) E\left[r_{2}\right]\left(E\left[r_{1}\right]-r_{0}\right) x_{1}^{*} \\
& -\lambda(1-C)^{2} E\left[r_{2}\right]^{2} D\left[r_{1}\right]\left(x_{1}^{*}\right)^{2} \\
= & 101.555 .
\end{aligned}
$$

Let $\lambda=0.1$. The returns $r_{1}=(0.91,1.012,1.076)$ and $r_{2}=(0.894,1.03,1.1)$ of the stock 600023 , which the investor 
TABLE 2: The optimal decisions $x_{1}^{*}$ with various values of $\lambda$.

\begin{tabular}{lccccc}
\hline Case & $\lambda=5$ & $\lambda=1$ & $\lambda=0.5$ & $\lambda=0.1$ & $\lambda=0.01$ \\
\hline$(1)$ & 11.1001 & 55.5006 & 99.7 & 99.7 & 99.7 \\
$(2)$ & 0.4679 & 2.3395 & 4.6790 & 23.3952 & 99.7 \\
$(3)$ & 0.1403 & 0.7013 & 1.4027 & 7.0133 & 70.1332 \\
$(4)$ & 0 & 0 & 0 & 0 & 0 \\
$(5)$ & 0.3312 & 1.6559 & 3.3118 & 16.5590 & 99.7 \\
$(6)$ & 0.1874 & 0.9372 & 1.8744 & 9.3720 & 93.7199 \\
$(7)$ & 0 & 0 & 0 & 0 & 0 \\
$(8)$ & 3.9037 & 19.5186 & 39.0372 & 99.7 & 99.7 \\
$(9)$ & 0.4846 & 2.4228 & 4.8457 & 24.2283 & 99.7 \\
$(10)$ & 0.4094 & 2.0472 & 4.0944 & 20.4722 & 99.7 \\
\hline
\end{tabular}

TABLE 3: The optimal utilities with various values of $\lambda$.

\begin{tabular}{lccccc}
\hline Case & $\lambda=5$ & $\lambda=1$ & $\lambda=0.5$ & $\lambda=0.1$ & $\lambda=0.01$ \\
\hline$(1)$ & 100.7579 & $\mathbf{1 0 0 . 9 8 4 5}$ & $\mathbf{1 0 1 . 2 6 4 5}$ & $\mathbf{1 0 1 . 6 4 8 6}$ & $\mathbf{1 0 1 . 7 3 5 1}$ \\
$(2)$ & $\mathbf{1 0 1 . 5 7 3 5}$ & $\mathbf{1 0 1 . 5 8 6 8}$ & $\mathbf{1 0 1 . 6 0 3 4}$ & $\mathbf{1 0 1 . 7 3 6 4}$ & $\mathbf{1 0 2 . 6 8 5 2}$ \\
$(3)$ & $\mathbf{1 0 1 . 5 4 5 4}$ & $\mathbf{1 0 1 . 5 4 6 2}$ & $\mathbf{1 0 1 . 5 4 7 2}$ & $\mathbf{1 0 1 . 5 5 5}$ & $\mathbf{1 0 1 . 6 4 3 1}$ \\
$(4)$ & $\mathbf{1 0 1 . 0 9 6 3}$ & $\mathbf{1 0 1 . 0 9 6 3}$ & $\mathbf{1 0 1 . 0 9 6 3}$ & $\mathbf{1 0 1 . 0 9 6 3}$ & $\mathbf{1 0 1 . 0 9 6 3}$ \\
$(5)$ & 100.7028 & 100.7093 & 100.7174 & 100.7821 & $\mathbf{1 0 1 . 3 8 2}$ \\
$(6)$ & 100.7017 & 100.7036 & 100.706 & 100.725 & $\mathbf{1 0 0 . 9 3 8 8}$ \\
$(7)$ & 100.7012 & 100.7012 & 100.7012 & 100.7012 & 100.7012 \\
$(8)$ & 100.7752 & $\mathbf{1 0 1 . 0 7 1}$ & $\mathbf{1 0 1 . 4 4 0 7}$ & $\mathbf{1 0 3 . 5 1 3 9}$ & $\mathbf{1 0 4 . 3 8 2 2}$ \\
$(9)$ & $\mathbf{1 0 0 . 8 5 0 4}$ & $\mathbf{1 0 0 . 8 6 4}$ & $\mathbf{1 0 0 . 8 8 1 1}$ & $\mathbf{1 0 1 . 0 1 7 9}$ & $\mathbf{1 0 1 . 9 6 4 4}$ \\
$(10)$ & $\mathbf{1 0 1 . 6 2 1 6}$ & $\mathbf{1 0 1 . 6 2 7 8}$ & $\mathbf{1 0 1 . 6 3 5 6}$ & $\mathbf{1 0 1 . 6 9 8}$ & $\mathbf{1 0 2 . 1 9 4 6}$ \\
\hline & & & & &
\end{tabular}

wants to invest in, are mutually independent. The data are shown in Table 1 as "case (4)." Since $r_{0}<((1-C) /(1+$ C)) $E\left[r_{2}\right]=1.00744$ and $\left(E\left[r_{1}\right]-r_{0}\right) / 2 \lambda(1-C) E\left[r_{2}\right] D\left[r_{1}\right]=$ $-3.6338<0$, by Theorem $4, x_{1}^{*}=0$. According to the definition of utility and its expression in model (22), the final utility is

$$
U\left(x_{1}^{*}\right)=\frac{1-C}{1+C} E\left[r_{2}\right] r_{0} W=101.0963 .
$$

Let $\lambda=0.1$. For the remaining 7 stocks, the values of $x_{1}^{*}$ and the final utilities can be calculated in the same way. The values of $x_{1}^{*}$ are listed in the 5th column of Table 2, and the final utilities are listed in the 5 th column of Table 3.

Let $\lambda=5,1,0.5$, and 0.01 , respectively. For the 10 stocks, Table 2 provides the values of $x_{1}^{*}$. Correspondingly the final utilities are shown in Table 3.

From Tables 2 and 3 , in any case, the larger $\lambda$ is, the smaller $x_{1}^{*}$ is and the lower the final utility is. This is consistent with the fact that the larger $\lambda$, the more risk-averse the investor. So the investor invests more wealth in the risk-free security when $\lambda$ is larger.

In order to illustrate the influence of the riskfree security on the optimal investment policy, some experiments are conducted. Here the returns $r_{1}=(0.973,1.04,1.12)$ and $r_{2}=(0.887,1.015,1.113)$ of the selected stock 600139, which are shown in Table 1 as "case (8)," are mutually independent. Let $\lambda=1$, and $r_{0}=1.0055,1.005,1.0045,1.004,1.0035,1.003,1.0025,1.002$,
TABLE 4: The optimal decisions $x_{1}^{*}$ with various values of $r_{0}$ when $\lambda=1$.

\begin{tabular}{lcc}
\hline$r_{0}$ & $x_{1}^{*}$ & $U\left(x_{1}^{*}\right)$ \\
\hline 1.0055 & 17.4424 & 101.3983 \\
1.005 & 17.9619 & 101.3156 \\
1.0045 & 18.4810 & 101.2335 \\
1.004 & 18.9999 & 101.1520 \\
1.0035 & 19.5186 & 101.0710 \\
1.003 & 20.0370 & 100.9906 \\
1.0025 & 20.5551 & 100.9107 \\
1.002 & 21.0730 & 100.8314 \\
\hline
\end{tabular}

respectively. By calculating, $(1+C) /(1-C) \times 1.002=$ $1.00803>E\left[r_{2}\right]=1.0075>r_{0}$, and $0<\left((1-C) E\left[r_{2}\right] E\left[r_{1}\right]-\right.$ $\left.r_{0}^{2}(1+C)\right) / 2 \lambda(1-C)^{2} E\left[r_{2}\right]^{2} D\left[r_{1}\right]<W /(1+C) \approx 99.7$. By Theorem 5,

$$
x_{1}^{*}=\frac{(1-C) E\left[r_{2}\right] E\left[r_{1}\right]-r_{0}^{2}(1+C)}{2 \lambda(1-C)^{2} E\left[r_{2}\right]^{2} D\left[r_{1}\right]} .
$$

According to the definition of utility and its expression in model (27), the final utilities are calculated as follows:

$$
\begin{aligned}
U\left(x_{1}^{*}\right)= & r_{0}^{2} W+(1-C) E\left[r_{2}\right] E\left[r_{1}\right] x_{1}^{*} \\
& -r_{0}^{2}(1+C) x_{1}^{*} \\
& -\lambda(1-C)^{2} E\left[r_{2}\right]^{2} D\left[r_{1}\right]\left(x_{1}^{*}\right)^{2} .
\end{aligned}
$$

The computational results are listed in Table 4. According to the data in Table $4, x_{1}^{*}$ increases as $r_{0}$ decreases. The main reasons are as follows.

Let $r_{0}-1$ be the interest rate. When interest rate rises, the discount rate also rises. The investor evaluates the stock value according to the discount rate, so the stock value will decline. As a consequence, the stock price drops correspondingly. Conversely, when interest rate falls, the stock price will rise; when interest rate rises, a part of the wealth will go to the bank from the stock market. Thereby, the market demand for stock will be reduced and the stock price will fall. Conversely, when interest rate falls, the profit ability of savings will be reduced and a part of the wealth will go back to the market. Thereby the demand for the stock will be expanded and the stock price will rise.

In order to illustrate the influence of the transaction costs on the optimal utility, some experiments are provided. The returns $r_{1}=(0.973,1.04,1.12)$ and $r_{2}=(0.887,1.015,1.113)$ of the selected stock 600139 are mutually independent. These data are shown in Table 1 as "case (8)." Let $\lambda=1$, and $C=0.0213,0.0214,0.021,0.02,0.01,0.005$, respectively. Then $(1+C) /(1-C) \times r_{0}>E\left[r_{2}\right]=1.0075>r_{0}$, and $0<$ $\left((1-C) E\left[r_{2}\right] E\left[r_{1}\right]-r_{0}^{2}(1+C)\right) / 2 \lambda(1-C)^{2} E\left[r_{2}\right]^{2} D\left[r_{1}\right]<$ $W /(1+C) \approx 99.7$. By Theorem 5 ,

$$
x_{1}^{*}=\frac{(1-C) E\left[r_{2}\right] E\left[r_{1}\right]-r_{0}^{2}(1+C)}{2 \lambda(1-C)^{2} E\left[r_{2}\right]^{2} D\left[r_{1}\right]} .
$$


TABLE 5: The optimal decisions $x_{1}^{*}$ with various values of $C$ when $\lambda=1$.

\begin{tabular}{lcc}
\hline$C$ & $x_{1}^{*}$ & $U\left(x_{1}^{*}\right)$ \\
\hline 0.0001 & 20.5099 & 101.4931 \\
0.001 & 20.5284 & 101.3113 \\
0.005 & 17.4681 & 100.9962 \\
0.01 & 12.2684 & 100.8453 \\
0.02 & 1.5465 & 100.7035 \\
0.021 & 0.4500 & 100.7014 \\
0.0213 & 0.1202 & 100.7012 \\
0.0214 & 0.0102 & 100.7012 \\
0.0215 & 0 & 100.7012 \\
\hline
\end{tabular}

According to the definition of utility and its expression in (27), the final utilities are calculated as follows:

$$
\begin{aligned}
U\left(x_{1}^{*}\right)= & r_{0}^{2} W+(1-C) E\left[r_{2}\right] E\left[r_{1}\right] x_{1}^{*} \\
& -r_{0}^{2}(1+C) x_{1}^{*} \\
& -\lambda(1-C)^{2} E\left[r_{2}\right]^{2} D\left[r_{1}\right]\left(x_{1}^{*}\right)^{2} .
\end{aligned}
$$

The computational results are listed in Table 5. When $C=$ 0.0215 , by calculating, $(1+C) /(1-C) \times r_{0}>E\left[r_{2}\right]=$ $1.0075>r_{0}$, and $\left((1-C) E\left[r_{2}\right] E\left[r_{1}\right]-r_{0}^{2}(1+C)\right) / 2 \lambda(1-$ $C)^{2} E\left[r_{2}\right]^{2} D\left[r_{1}\right]=-0.0999<0$. It is concluded that $x_{1}^{*}=0$ by using Theorem 5. According to the definition of utility and its expression in model (27), the final utility is $U\left(x_{1}^{*}\right)=r_{0}^{2} W=$ 100.7012. The computational results are listed in Table 5. Let $C=0.001,0.0001$, respectively. Then $(1+C) /(1-C) \times r_{0}<$ $E\left[r_{2}\right]=1.0075$, and $0<\left(E\left[r_{1}\right]-r_{0}\right) / 2 \lambda(1-C) E\left[r_{2}\right] D\left[r_{1}\right]<$ $W /(1+C) \approx 0.997$. Hence,

$$
x_{1}^{*}=\frac{E\left[r_{1}\right]-r_{0}}{2 \lambda(1-C) E\left[r_{2}\right] D\left[r_{1}\right]}
$$

$$
x_{1}^{*}=\left\{\begin{array}{l}
0, \\
\frac{W}{1+C}, \\
\frac{(1-C) E\left[r_{2}\right]-r_{0}^{\prime}(1+C)}{2 \lambda(1-C)^{2} D\left[r_{2}\right]},
\end{array}\right.
$$

In any case, under different values of $\lambda$, the calculated optimal decisions $x_{1}^{*}$ are shown in Table 6 . According to the definition of utility and its expression in model (47), the final utilities are

$$
\begin{aligned}
U^{\prime}\left(x_{0}^{*}, x_{1}^{*}\right)= & (1-C) E\left[r_{2}\right] x_{1}^{*}+r_{0}^{\prime} x_{0}^{*} \\
& -\lambda(1-C)^{2} D\left[r_{2}\right]\left(x_{1}^{*}\right)^{2} .
\end{aligned}
$$

The calculated utilities are listed in Table 7. by Theorem 4 . According to the definition of utility and its expression in model (22), the final utilities are calculated as follows:

$$
\begin{aligned}
U\left(x_{1}^{*}\right)= & \frac{1-C}{1+C} E\left[r_{2}\right] r_{0} W \\
& +(1-C) E\left[r_{2}\right]\left(E\left[r_{1}\right]-r_{0}\right) x_{1}^{*} \\
& -\lambda(1-C)^{2} E\left[r_{2}\right]^{2} D\left[r_{1}\right]\left(x_{1}^{*}\right)^{2} .
\end{aligned}
$$

The computational results are listed in Table 5. From the data in Table 5, $U\left(x_{1}\right)$ increases as the transaction costs rate $C$ decreases.

5.3. Computational Results with the Single-Stage Model. The investor takes 70 days as one period and makes a oneoff decision at the beginning of the period. The investor wants to allocate the wealth between one stock and one principal-protected financial product with holding period of 70 days. The annualized return rate of the financial product is 0.0417 ; that is, the return $r_{0}^{\prime}=1.008$. The investor wants to maximize the final wealth utility. This is a single-period portfolio selection problem.

The returns are characterized by triangular possibility distributions, which are shown in the 3rd column of Table 1. Let $x_{i}$ be the decision variable which shows the wealth amount invested in the $i$ th security. The final wealth is $W^{\prime}=$ $(1-C) r_{2} x_{1}+r_{0}^{\prime} x_{0}$. The final wealth utility is $E\left[W^{\prime}\right]-\lambda D\left[W^{\prime}\right]$. The single-stage portfolio selection model can be written as

$$
\begin{array}{ll}
\operatorname{maximize} & U^{\prime}\left(x_{0}, x_{1}\right) \\
& =(1-C) E\left[r_{2}\right] x_{1}+r_{0}^{\prime} x_{0} \\
& -\lambda(1-C)^{2} D\left[r_{2}\right] x_{1}^{2} \\
\text { subject to } & x_{0}+(1+C) x_{1}=W \\
& x_{i} \geq 0, \quad i=0,1 .
\end{array}
$$

The optimal solution $x_{0}^{*}=W-(1+C) x_{1}^{*}$ and

if $\frac{1-C}{1+C} E\left[r_{2}\right] \leq r_{0}^{\prime}$

if $\frac{(1-C) E\left[r_{2}\right]-r_{0}^{\prime}(1+C)}{2 \lambda(1-C)^{2} D\left[r_{2}\right]} \geq \frac{W}{1+C}$

otherwise.

5.4. Discussion. From Tables 2 and 6, the investment policies in Table 2 are more dispersive in the stock than those in Table 6. The reason for this result is that the investment policy of the first period can be adjusted at the end of the first period. When the performance of the stock is better at the first period, while it is worse at the second period, the decision maker can make the invested wealth amount $x_{1}^{*}$ larger. According to Tables 3 and 7, the optimal utilities provided by the two-stage 
TABLE 6: The optimal decisions $x_{1}^{*}$ with various values of $\lambda$.

\begin{tabular}{lccccc}
\hline Case & $\lambda=5$ & $\lambda=1$ & $\lambda=0.5$ & $\lambda=0.1$ & $\lambda=0.01$ \\
\hline$(1)$ & 0 & 0 & 0 & 0 & 0 \\
$(2)$ & 0.1479 & 0.7394 & 1.4788 & 7.3941 & 73.9412 \\
$(3)$ & 0.1418 & 0.7091 & 1.4182 & 7.0911 & 70.9111 \\
$(4)$ & 0 & 0 & 0 & 0 & 0 \\
$(5)$ & 0 & 0 & 0 & 0 & 0 \\
$(6)$ & 0 & 0 & 0 & 0 & 0 \\
$(7)$ & 0 & 0 & 0 & 0 & 0 \\
$(8)$ & 0 & 0 & 0 & 0 & 0 \\
$(9)$ & 0 & 0 & 0 & 0 & 0 \\
$(10)$ & 0.1600 & 0.8001 & 1.6002 & 8.0008 & 80.0080 \\
\hline
\end{tabular}

TABLE 7: The optimal utilities with various values of $\lambda$.

\begin{tabular}{lccccc}
\hline Case & $\lambda=5$ & $\lambda=1$ & $\lambda=0.5$ & $\lambda=0.1$ & $\lambda=0.01$ \\
\hline$(1)$ & 100.8 & 100.8 & 100.8 & 100.8 & 100.8 \\
$(2)$ & 100.8003 & 100.8015 & 100.8031 & 100.8154 & 100.9542 \\
$(3)$ & 100.8003 & 100.8014 & 100.8028 & 100.8139 & 100.9391 \\
$(4)$ & 100.8 & 100.8 & 100.8 & 100.8 & 100.8 \\
$(5)$ & 100.8 & 100.8 & 100.8 & 100.8 & 100.8 \\
$(6)$ & 100.8 & 100.8 & 100.8 & 100.8 & 100.8 \\
$(7)$ & 100.8 & 100.8 & 100.8 & 100.8 & 100.8 \\
$(8)$ & 100.8 & 100.8 & 100.8 & 100.8 & 100.8 \\
$(9)$ & 100.8 & 100.8 & 100.8 & 100.8 & 100.8 \\
$(10)$ & 100.8004 & 100.8019 & 100.8037 & 100.8187 & 100.9868 \\
\hline
\end{tabular}

model, which are listed in the bold type, are larger than those provided by the single-stage model correspondingly. The optimal utilities provided by the two-stage model, which are listed in italics, are larger than those obtained by investing all wealth in the risk-free security. In the only remaining "case (7)," the optimal utilities provided by the two-stage model are equal to those obtained by investing all wealth in the risk-free security.

\section{Conclusions}

This paper studies a two-period portfolio selection problem in fuzzy decision system and develops the two-stage fuzzy portfolio selection model with transaction costs. The major conclusions include the following several aspects:

(i) The optimal value expression of the second-stage programming problem is derived (Theorem 3). As a consequence, the proposed two-stage model is equivalent to a single-stage model.

(ii) The analytical optimal solution of the proposed twostage model is presented (Theorems 4, 5, and 6). From the analytical solution, the following observations are obtained. The optimal first-stage invested amount in the risky security is increasing with respect to the expected return of the risky security at the first period, while it is decreasing with respect to the corresponding variance. The optimal first-stage invested amount in the risky security is decreasing with respect to the risk aversion coefficient and the fixed return of riskfree security.

(iii) The decision provided by the two-stage fuzzy model is consistent with the fact that the risk-averse investor will invest more wealth in the risk-free security. This conclusion is based on the computational results of the numerical experiments (Table 2). The computational results also show that the optimal invested amount in the risky security increases as the risk-free return decreases, the optimal utility increases as the risk-free return increases (Table 4), and the optimal utility increases as the transaction costs decrease (Table 5).

(iv) The experiments' results illustrate that the optimal first-stage investment amounts in risky security given by the proposed two-stage model are larger than those given by the single-stage model. This conclusion can be obtained through comparing Table 2 with Table 6 . The reason for this conclusion is that the proposed two-stage model gives the investor an option to take recourse action at the second period. Based on Tables 3 and 7, the optimal utilities provided by the two-stage fuzzy model are higher than those provided by the single-stage model in most instances.

\section{Notations}

C: The fixed transaction costs rate of unit trading volume

$W$ : Initial wealth

$r_{0}$ : The fixed return of risk-free security

$r_{1}$ : The fuzzy return of the risky security at the first period

$r_{2}$ : The fuzzy return of the risky security at the second period

$x_{i}$ : The wealth amount invested in the $i$ th security in the first-stage, $i=0,1$

$y_{i}$ : Adjustment amount of the $i$ th security in the second-stage, $i=0,1$.

\section{Conflict of Interests}

The authors declare that there is no conflict of interests regarding the publication of this paper.

\section{Acknowledgments}

This work is supported by the National Natural Science Foundation of China (no. 61374184) and the Natural Science Foundation and the Education Department of Hebei Province (no. A2014201166 and no. QN20131055).

\section{References}

[1] H. M. Markowitz, "Portfolio selection," The Journal of Finance, vol. 7, no. 1, pp. 77-91, 1952. 
[2] J. Mossin, "Optimal multiperiod portfolio policies," The Journal of Business, vol. 41, no. 2, pp. 215-229, 1968.

[3] G. B. Dantzig and G. Infanger, "Multi-stage stochastic linear programs for portfolio optimization," Annals of Operations Research, vol. 45, no. 1-4, pp. 59-76, 1993.

[4] D. Li and W.-L. Ng, "Optimal dynamic portfolio selection: multiperiod mean-variance formulation," Mathematical Finance, vol. 10, no. 3, pp. 387-406, 2000.

[5] U. Çelikyurt and S. Özekici, "Multiperiod portfolio optimization models in stochastic markets using the mean-variance approach," European Journal of Operational Research, vol. 179, no. 1, pp. 186-202, 2007.

[6] D. Bertsimas and D. Pachamanova, "Robust multiperiod portfolio management in the presence of transaction costs," Computers \& Operations Research, vol. 35, no. 1, pp. 3-17, 2008.

[7] X. Cui, J. Gao, X. Li, and D. Li, "Optimal multi-period meanvariance policy under no-shorting constraint," European Journal of Operational Research, vol. 234, no. 2, pp. 459-468, 2014.

[8] L. A. Zadeh, "Fuzzy sets," Information and Control, vol. 8, pp. 338-353, 1965.

[9] L. A. Zadeh, "Fuzzy sets as a basis for a theory of possibility," Fuzzy Sets and Systems, vol. 1, no. 1, pp. 3-28, 1978.

[10] D. Dubois and H. Prade, Possibility Theory, Plenum Press, New York, NY, USA, 1988.

[11] B. Liu and Y.-K. Liu, "Expected value of fuzzy variable and fuzzy expected value models," IEEE Transactions on Fuzzy Systems, vol. 10, no. 4, pp. 445-450, 2002.

[12] B. Liu, Uncertainty Theory: An Introduction to Its Axiomatic Foundations, vol. 154 of Studies in Fuzziness and Soft Computing, Springer, Berlin, Germany, 2004.

[13] M. Inuiguchi and T. Tanino, "Portfolio selection under independent possibilistic information," Fuzzy Sets and Systems, vol. 115, no. 1, pp. 83-92, 2000.

[14] A. Bilbao-Terol, B. Pérez-Gladish, M. Arenas-Parra, and M. V. Rodríguez-Uría, "Fuzzy compromise programming for portfolio selection," Applied Mathematics and Computation, vol. 173, no. 1, pp. 251-264, 2006.

[15] X.-L. Wu and Y.-K. Liu, "Spread of fuzzy variable and expectation-spread model for fuzzy portfolio optimization problem," Journal of Applied Mathematics and Computing, vol. 36, no. 1-2, pp. 373-400, 2011.

[16] X. Huang, "An entropy method for diversified fuzzy portfolio selection," International Journal of Fuzzy Systems, vol. 14, no. 1, pp. 160-165, 2012.

[17] M. K. Mehlawat and P. Gupta, "Fuzzy chance-constrained multiobjective portfolio selection model," IEEE Transactions on Fuzzy Systems, vol. 22, no. 3, pp. 653-671, 2014.

[18] X. Deng and R. Li, "Gradually tolerant constraint method for fuzzy portfolio based on possibility theory," Information Sciences, vol. 259, pp. 16-24, 2014.

[19] W. Qian and M. Yin, "Portfolio selection based on distance between fuzzy variables," Mathematical Problems in Engineering, vol. 2014, Article ID 403208, 12 pages, 2014.

[20] T. Li, W. Zhang, and W. Xu, "A fuzzy portfolio selection model with background risk," Applied Mathematics and Computation, vol. 256, pp. 505-513, 2015.

[21] W. Chen, H. Ma, Y. Yang, and M. Sun, "Application of artificial bee colony algorithm to portfolio adjustment problem with transaction costs," Journal of Applied Mathematics, vol. 2014, Article ID 192868, 12 pages, 2014.
[22] P. Gupta, G. Mittal, and M. K. Mehlawat, "A multicriteria optimization model of portfolio rebalancing with transaction costs in fuzzy environment," Memetic Computing, vol. 6, no. 1, pp. 61-74, 2014.

[23] W.-G. Zhang, Y.-J. Liu, and W.-J. Xu, "A possibilistic meansemivariance-entropy model for multi-period portfolio selection with transaction costs," European Journal of Operational Research, vol. 222, no. 2, pp. 341-349, 2012.

[24] Z. Qin, X. Li, and X. Ji, "Portfolio selection based on fuzzy crossentropy," Journal of Computational and Applied Mathematics, vol. 228, no. 1, pp. 139-149, 2009.

[25] W.-G. Zhang, W.-L. Xiao, and W.-J. Xu, "A possibilistic portfolio adjusting model with new added assets," Economic Modelling, vol. 27, no. 1, pp. 208-213, 2010.

[26] A. Barua, L. S. Mudunuri, and O. Kosheleva, "Why trapezoidal and triangular membership functions work so well: towards a theoretical explanation," Journal of Uncertain Systems, vol. 8, no. 3, pp. 164-168, 2014. 


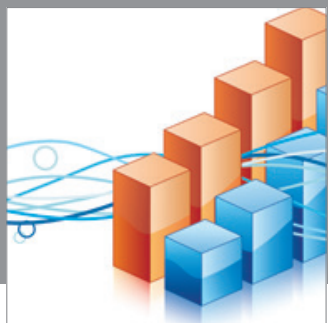

Advances in

Operations Research

mansans

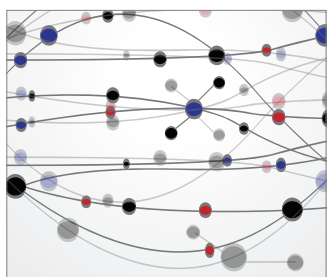

The Scientific World Journal
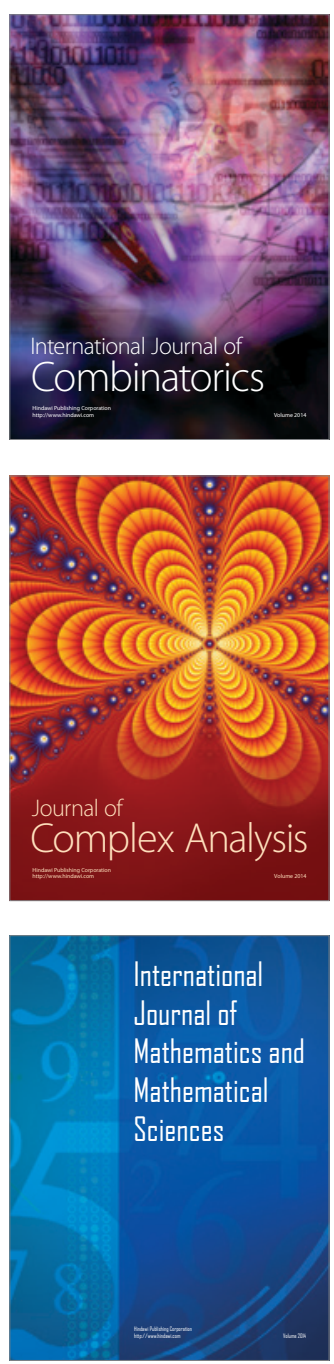
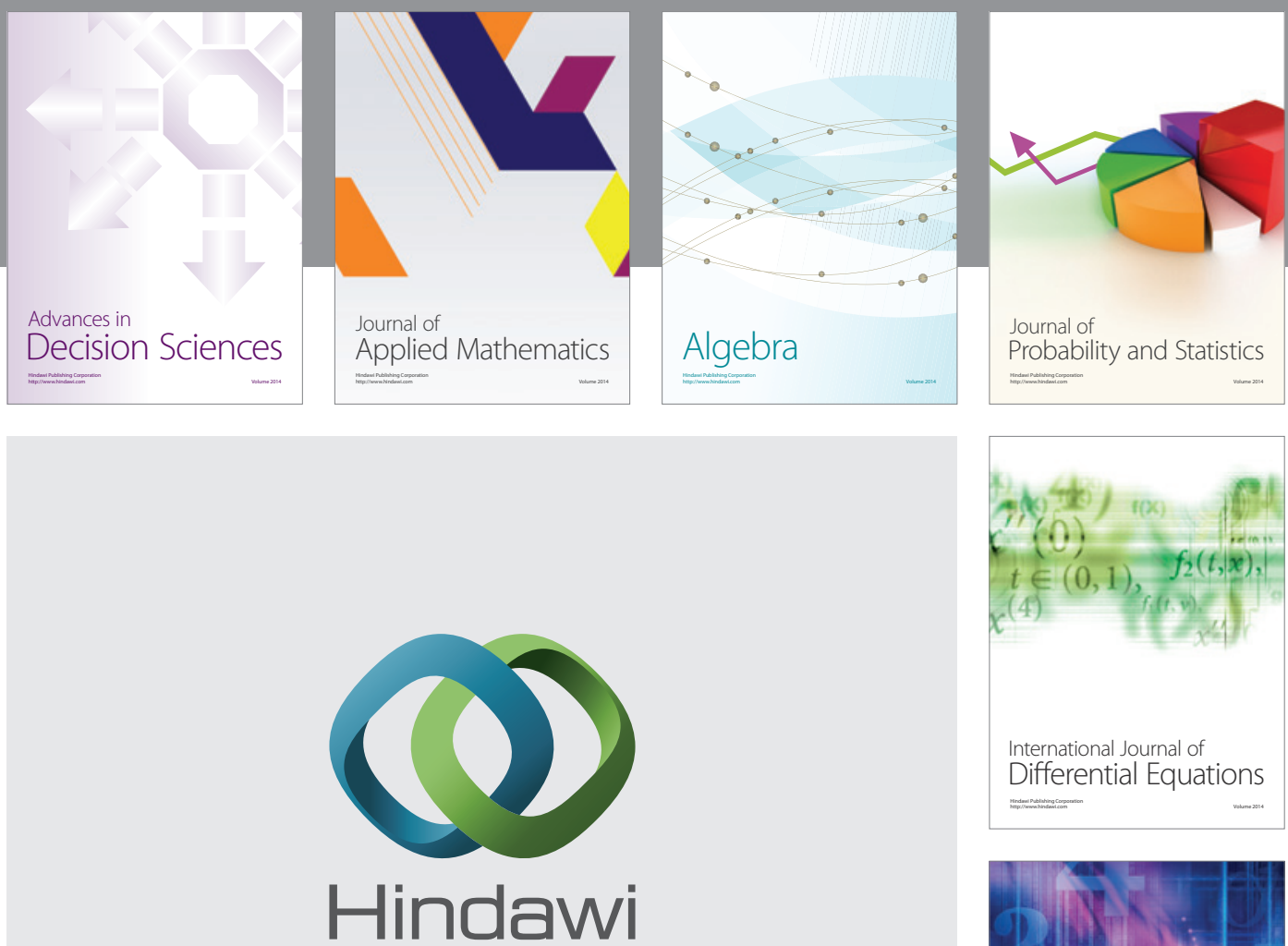

Submit your manuscripts at http://www.hindawi.com
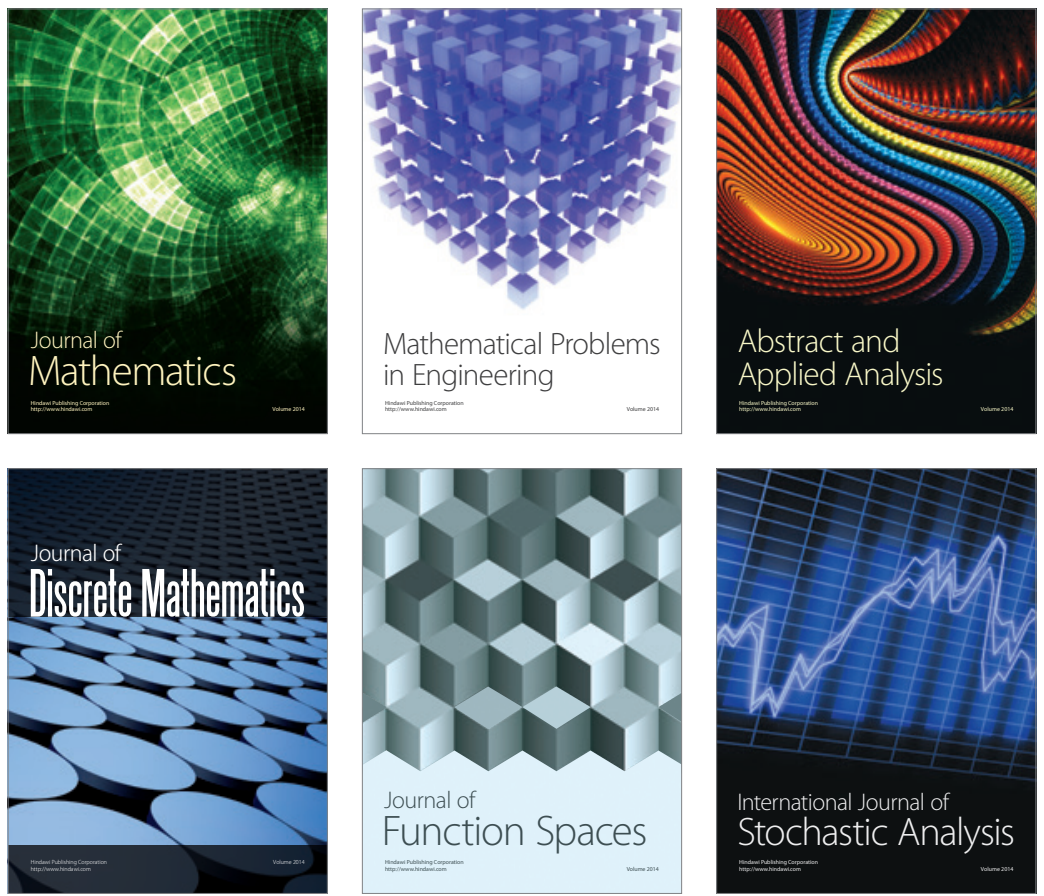

Journal of

Function Spaces

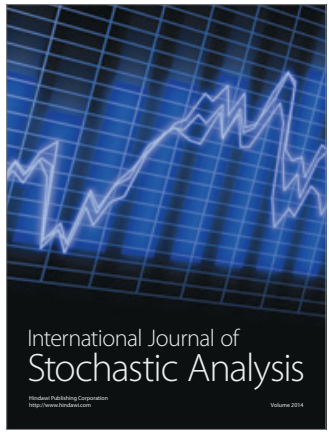

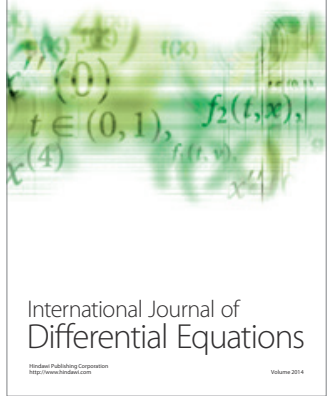
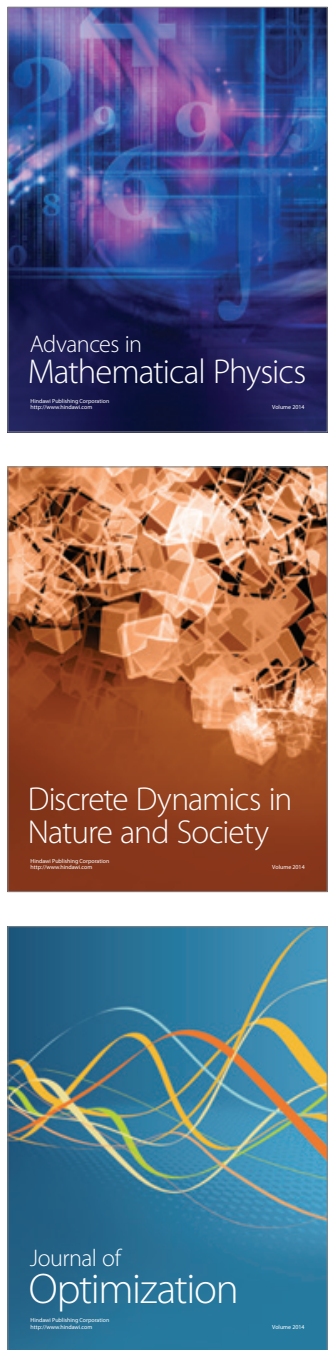